\title{
Impact of suffusion on the cyclic and post-cyclic behaviour of an internally unstable soil
}

\author{
A. MEHDIZADEH* ${ }^{*}$ M. M. DISFANI $\uparrow$, R. EVANS $\ddagger$ and A. ARULRAJAH§
}

\begin{abstract}
Suffusion is defined as the migration of fine particles caused by seepage flow through pre-existing pores of a soil structure made of coarse particles. This particle transportation changes the fine particle content and its distribution, possibly impacting the mechanical behaviour of eroded soil. Although limited research has been conducted on the post-erosion mechanical consequences under monotonic shearing, little attention has been paid to the impact of suffusion on the cyclic resistance and liquefaction potential of internally unstable soils. This paper investigates the cyclic and post-cyclic behaviour of a gap-graded cohesionless soil using combined triaxial-erosion apparatus. An internally unstable soil was chosen for the erosion test and was subjected to different seepage flow velocities and durations followed by cyclic loading and post-cyclic shearing. During cyclic loading, the eroded specimens with different residual fine contents behaved in a similar manner to a soil specimen constructed only of coarse particles. Regardless of the seepage velocity and duration, the erosion of fine particles resulted in significant increase in cyclic resistance. It is understood that eroded specimens with lower intergranular void ratios show higher resistance during cyclic loading, highlighting the importance of the intergranular void ratio in understanding the post-erosion mechanical behaviour of soils.
\end{abstract}

KEYWORDS: erosion; liquefaction; seepage

Published with permission by the ICE under the CC-BY 4.0 license. (http://creativecommons.org/licenses/by/4.0/)

\section{INTRODUCTION}

Suffusion is defined as the erosion of fine particles through pre-existing pores between coarse particles caused by seepage flow. The impact of fine particle removal on the mechanical behaviour of granular soils depends on the role fine particles play in the soil structure. The impact of the erosion of fine particles on the mechanical behaviour of granular material under monotonic shearing has been reported by Ke \& Takahashi (2014) and Mehdizadeh et al. (2017b). Mehdizadeh et al. (2017b) established that the intergranular void ratio proposed by Mitchell (1993) is a better index to determine the post-erosion mechanical behaviour of an internally unstable soil. More importantly, it was understood that the undrained behaviour of the original specimen changed from a strain-hardening behaviour to a flow-type behaviour with limited deformation after suffusion. However, the initial undrained peak strength improved slightly, and the flow potential decreased during the early stages of erosion (Mehdizadeh et al., 2017b). While previous findings indicate that the erosion of fine particles

Manuscript received 10 July 2018; first decision 27 May 2019; accepted 29 May 2019.

Published online at www.geotechniqueletters.com on 15 July 2019.

${ }^{*}$ Department of Infrastructure Engineering, University of Melbourne, Melbourne, Australia

(Orcid:0000-0001-7711-8128).

$\dagger$ Department of Infrastructure Engineering, University of Melbourne, Melbourne, Australia

(Orcid:0000-0002-9231-8598).

tDepartment of Civil and Construction Engineering, Swinburne University of Technology, Melbourne, Australia (Orcid:0000-0003-1998-2537).

§Department of Civil and Construction Engineering, Swinburne University of Technology, Melbourne, Australia (Orcid:0000-0003-1512-9803). significantly impacts the drained and undrained behaviours of internally unstable soils, so far, no study was conducted on the impact of suffusion on the potential of liquefaction in soils susceptible to suffusion. As the risk and safety assessment of embankment dams under cyclic loading have been always a matter of attention, this study attempts to provide new insight into the impact of suffusion on the mechanical behaviour of internally unstable soils under cyclic loadings. In a soil composed of coarse and fine particles, the fine particles may be (a) just filling the void and thus be inactive, $(b)$ providing lateral support to the force chains made by the coarse particles, thus considered semi-active or (c) completely active by contributing directly to the load-transfer mechanism. This indicates that the artificial removal of fine particles or the alteration of fine content during sample preparation cannot necessarily mimic a real natural condition such as suffusion. However, past experimental studies investigated the influence of cohesionless fine content on liquefaction potential or whether the cyclic resistance of granular soils could considerably help understand the cyclic behaviour of soils after suffusion.

The presence of silt size particles has been found to slightly improve liquefaction resistance in sandy soils (Kuerbis et al., 1988; Pitman et al., 1994). However, Evans \& Zhou (1995) reported that gravelly soils become more susceptible to liquefaction with an increase in sand content. Lade \& Yamamuro (1997) showed that soil specimens with higher fine content liquefied at lower values of axial strain, even under higher relative density. In other laboratory investigations (e.g. Chang, 1990; Georgiannou et al., 1990, 1991a, 1991b; Chameau \& Sutterer, 1994; Finn et al., 1994; Koester, 1994; Vaid, 1994; Zlatovic \& Ishihara, 1995), it was shown that an increase in the fine content decreased the steady-state strength and cyclic resistance of silty sand. A statistical analysis was conducted by Andrianopoulos et al. (2001) on a large data set of triaxial tests suggesting that the presence of fine content improved liquefaction resistance when the mean 
effective consolidation stress was less than $86 \mathrm{kPa}$. For consolidation pressures higher than $86 \mathrm{kPa}$, liquefaction potential increased when the fine content increased. Cyclic triaxial tests conducted by Xenaki \& Athanasopoulos (2003) indicated that in soil specimens with the same global void ratio, an increase in fine content from 0 to $44 \%$ decreased the liquefaction resistance of mixtures compared to that of clean sand. This trend was found to be the opposite for fine contents greater than 44\%. Lade \& Yamamuro (1997), Zlatovic \& Ishihara (1995), Thevanayagam et al. (1997), Amini \& Qi (2000) and Naeini \& Baziar (2004) reported that the nature of silty sand is very different in comparison with clean sand and the global void ratio is unable to represent particle contact and interaction correctly. Therefore, recently it has been more common to consider the intergranular void ratio as a new index to describe the behaviour of silty sands (Thevanayagam, 1998; Chu \& Leong, 2002; Belkhatir et al., 2010). For example, a series of stress-controlled cyclic triaxial tests were conducted by Belkhatir et al. (2010) on silty sand with varying silt content. The intergranular void ratio was found to increase with silt content in the range $0-50 \%$ fine content and the risk of liquefaction increased due to an increase in the intergranular void ratio.

Current literature indicates that the impact of non-plastic fine particles on cyclic resistance is a divisive topic with conflicting research results supporting opposing arguments. This is believed to be due to the different contributions of fine particles in the soil structure in each of these research studies and also the impact of other influential factors such as the specimen-preparation method. The impact of fine content on cyclic resistance and liquefaction potential of a soil becomes even more complicated when the change in fine content is caused by natural forces such as water flow leading to suffusion. Suffusion is a natural phenomenon with inherent non-uniformity along the seepage path. It may occur anywhere in an embankment dam. If not impossible, it is very difficult to exactly simulate a real erosion process. This research attempted to erode internally unstable soil samples mimicking the natural process to investigate the impact of loss of suffusion on the cyclic behaviour of soil samples. A triaxial chamber was modified to perform erosion and shearing phases successively to minimise the loss of saturation and soil disturbance (Mehdizadeh et al., 2017a). This modified apparatus was used to investigate the post-erosion undrained behaviour during cyclic loading and monotonic shearing afterwards.

\section{MATERIAL PROPERTIES AND TESTING EQUIPMENT}

A gap-graded cohesionless soil with $25 \%$ non-plastic fine content and a soil gradation shown in Fig. 1 was selected for this research. The susceptibility of fine particles to suffusion in this study was examined using the methods proposed by Kezdi (1969), Kenney \& Lau (1986) and Moraci et al. (2014), all indicating that the chosen soil gradation was internally unstable. It is worth noting that the sizes of the fine particles ranged from 0.075 to $0.3 \mathrm{~mm}$, which is greater than the size of a typical silt particle. However, it could be classified as fine content with respect to coarse particle size and soil gradation.

Technical modifications of the triaxial apparatus and testing procedure including specimen preparation, saturation, consolidation, erosion, shearing and the repeatability of erosion tests were fully described by Mehdizadeh et al. (2017a) and Mehdizadeh (2018). Triaxial soil specimens $75 \mathrm{~mm}$ in diameter and $150 \mathrm{~mm}$ high were prepared using the moist tamping method with $6 \%$ water content according to Ladd (1978) and Jiang et al. (2003). Each specimen was fully saturated and consolidated to $150 \mathrm{kPa}$ to remove any stress history experienced during sample preparation (Frost \& Park, 2003). After consolidation, an erosion phase with four different downward seepage conditions were applied at the top of the soil specimens according to the test programme presented in Table 1. After the erosion was completed, undrained cyclic and post-cyclic monotonic shearing was performed, and the results were compared with the undrained behaviour of a non-eroded specimen. A low cyclic-loading frequency and a slow post-cyclic undrained shearing rate were chosen to provide sufficient time for pore-pressure equalisation.

\section{TESTS RESULTS}

With the total volume of specimens at the end of the erosion phase obtained using the photogrammetry technique combined with the measurement of the mass of eroded particles and the specific gravity of the particles, the global and intergranular void ratios can be estimated (Mehdizadeh et al., 2017a). The precision of volumetric strain measurement has been discussed thoroughly by Mehdizadeh et al. (2015) and Mehdizadeh (2018). The variation of fine content and the global and intergranular void ratios at the end of the erosion phase are shown in Table 2.

The global void ratio increased due to the erosion of the fine particles as expected. However, the intergranular void ratio decreased as the erosion progressed. This is plausible considering the vertical strains that occurred during the erosion phase. Mehdizadeh \& Disfani (2018) employed three-dimensional X-ray tomography to study the impact of suffusion on the soil structure and they found that the removal of fine particles which provide lateral support for force chains (made by coarse particles) triggered local

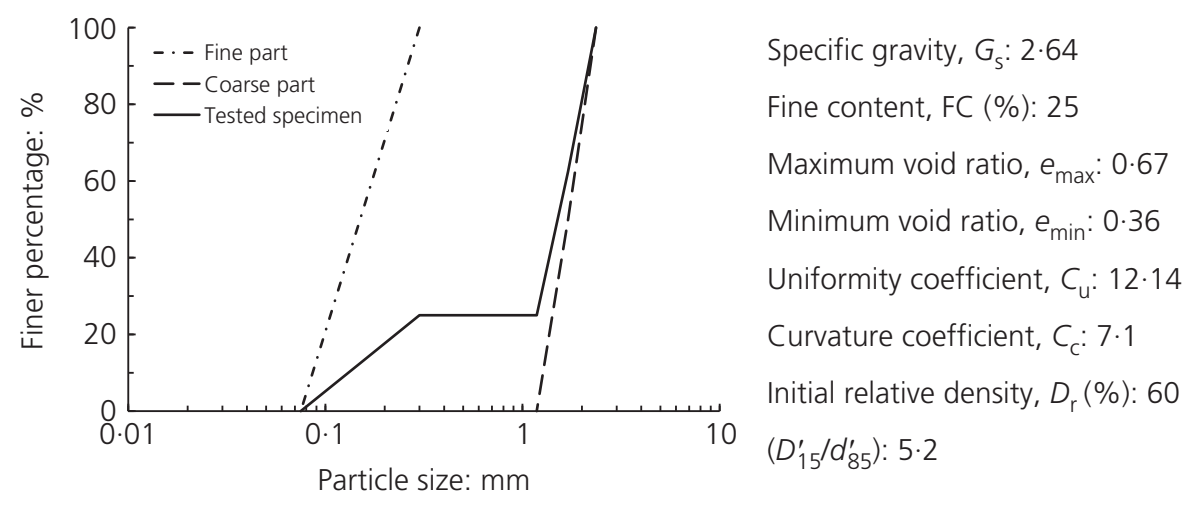

Fig. 1. Particle-size distribution and geometrical properties of tested soil (non-eroded specimen) 
Table 1. Experimental testing programme

\begin{tabular}{|c|c|c|c|c|c|c|c|}
\hline \multirow{2}{*}{$\begin{array}{l}\text { Test phase } \\
\text { Specimen }\end{array}$} & \multirow{2}{*}{$\begin{array}{c}\text { Consolidation } \\
\text { Consolidation } \\
\text { pressure: } \mathrm{kPa}\end{array}$} & \multicolumn{2}{|c|}{ Erosion } & \multicolumn{3}{|c|}{ Cyclic loading } & \multirow{2}{*}{\begin{tabular}{|l} 
Monotonic shearing \\
Rate: $\% / \mathrm{min}$
\end{tabular}} \\
\hline & & $\begin{array}{c}\text { Inflow velocity: } \\
\mathrm{mm} / \mathrm{min}\end{array}$ & $\begin{array}{c}\text { Erosion } \\
\text { duration: } \min \end{array}$ & $\mathrm{CSR}^{\mathrm{a}}$ & $\mathrm{f}^{\mathrm{b}}: \mathrm{Hz}$ & Duration: s & \\
\hline $\begin{array}{l}\text { E-Cyc-V52-T30 } \\
\text { E-Cyc-V52-T120 } \\
\text { E-Cyc-V92-T30 } \\
\text { E-Cyc-V92-T120 } \\
\text { NE-Cyc }\end{array}$ & 150 & $\begin{array}{r}52 \\
92 \\
-\end{array}$ & $\begin{array}{c}30 \\
120 \\
30 \\
120\end{array}$ & $0 \cdot 167$ & $0 \cdot 0083$ & $\begin{array}{l}3600 \\
\sim 780^{\mathrm{d}}\end{array}$ & $0 \cdot 26$ \\
\hline
\end{tabular}

${ }^{\mathrm{a}}$ Cyclic stress ratio.

${ }^{\mathrm{b}}$ Loading frequency.

${ }^{\mathrm{c}} \mathrm{E}-\mathrm{Cyc}-\mathrm{V} 52-\mathrm{T} 30$ means E(eroded)-Cyc(cyclic)-V(seepage velocity)-T(seepage duration).

${ }^{\mathrm{d}}$ The non-eroded specimen was liquefied after five cycles of loading.

Table 2. Pre- and post-erosion global and intergranular void ratios and fine content

\begin{tabular}{l|l|c|c|c|c|c}
\hline Specimen & $\mathrm{FC}_{\mathrm{i}}: \%$ & $\mathrm{FC}_{\mathrm{f}}: \%$ & $e_{\mathrm{i}}$ & $e_{\mathrm{f}}$ & $e_{\mathrm{gi}}$ & $e_{\mathrm{gf}}$ \\
\hline E-Cyc-V52-T30 & 25 & 20 & $0 \cdot 46$ & $0 \cdot 51$ & $0 \cdot 95$ & $0 \cdot 89$ \\
E-Cyc-V52-T120 & & $15 \cdot 4$ & & $0 \cdot 6$ & & $0 \cdot 891$ \\
E-Cyc-V92-T30 & & $18 \cdot 2$ & & $0 \cdot 55$ & $0 \cdot 895$ \\
E-Cyc-V92-T120 & & $25 \cdot 4$ & & 0.65 & & $0 \cdot 84$ \\
NE-Cyc & & & $0 \cdot 46$ & & $0 \cdot 95$ \\
\hline
\end{tabular}

where $\mathrm{FC}_{\mathrm{i}}$ is the initial fine content, $\mathrm{FC}_{\mathrm{f}}$ is the final fine content, $e_{\mathrm{i}}$ is the initial global void ratio, $e_{\mathrm{f}}$ is the final global void ratio, $e_{\mathrm{gi}}$ is the initial intergranular void ratio and $e_{\mathrm{gf}}$ is the final intergranular void ratio.

The intergranular void ratio $e_{\mathrm{g}}$ is equal to $(e+\mathrm{FC}) /(1-\mathrm{FC})$ (Mitchell, 1993).

instability and vertical distortions. This coarse particle rearrangement reduced the available voids between host coarse particles, and consequently, the intergranular void ratio.

The development of vertical strains and the excess porewater pressure during cyclic loading for the non-eroded and eroded specimens are shown in Fig. 2. Although the relative density and consolidation pressure of the soil specimens were $60 \%$ and $150 \mathrm{kPa}$, respectively, the non-eroded specimen liquefied after only five cycles of loading. In contrast, all eroded specimens developed excess pore pressure slowly with a decreasing trend with the fine content. The vertical strains in the extension path were almost zero for all eroded specimens and only $0 \cdot 125 \%$ axial strain was developed in the compressive path after 30 cycles of loading. It seems, for the materials tested in this research, suffusion made the tested soil specimens non-liquefiable under the applied cyclic loadings, regardless of the amount of residual fine particles. Similar improvements in cyclic resistance after erosion have also been reported by $\mathrm{Ke} \&$ Takahashi (2014). At first glance, it may be expected that the erosion of fine particles followed by an increase in the global void ratio moves the eroded specimens from the initial state to a looser state translating into higher liquefaction potential. However, it is believed that the erosion of fine particles and a reduction in the intergranular void ratio increased the interaction of coarse particles and improved the coarse particle interlocking at small strains, which led to a higher resistance to liquefaction. This is in agreement with the findings under monotonic shearing that the initial peak shear strength at small strains improved after suffusion (Mehdizadeh et al., $2017 \mathrm{~b}$ ). This is a plausible scenario as the angularity of coarse fraction was found to be higher than that of fine fraction (Mehdizadeh et al., 2017a).

Mehdizadeh et al. (2017b) performed a series of undrained monotonic triaxial tests on the eroded specimens under the same erosion conditions (specimens E-Mon-V52-T30, E-Mon-V52-T120, E-Mon-V92-T30 and E-Mon-V92-T120).
The final void ratios and fine content were found to be similar to the eroded specimens subjected to cyclic loading in this research. A comparison of the stress-strain relationship induced excess pore pressure (EPWP) and stress path results shows that the softening behaviour was more dominant for the eroded specimens that experienced cyclic loading (Figs 3 and 4). Figures 3 and 4 show that although excess pore pressure was only developed in the range of $20-30 \%$ of the consolidation pressure, during cyclic loading, it was high enough to reduce the effective stresses along the height of the eroded specimens, which resulted in the specimens exhibiting a softer behaviour during post-cyclic undrained shearing. However, all specimens (regardless of experiencing cyclic loading or not, seepage velocity and duration) eventually ended up on parallel steady-state lines, as suggested by Yang et al. (2006) for the sand-silt mixtures with various fine contents that the fine content has no influence on the slope of the steady-state lines.

\section{CRITICAL INVESTIGATION AND DISCUSSION}

To develop a better understanding of the post-erosion cyclic behaviour of the tested material, an additional soil specimen was prepared using only the coarse fraction (NE-Cyc-CF, $\mathrm{FCi}=0$ ) of the gradation shown in Fig. 1. The specimen was mixed with $3 \%$ water content and compacted by the moist tamping method to achieve a relatively high global void ratio of 0.73 after consolidation. The initial water content was estimated by trial and error to ensure segregation does not happen during sample preparation. Six per cent water content was used for samples with $25 \%$ fine content while the soil sample made only of coarse particles was mixed with $3 \%$ water content as the chance of segregation was minimal due to the absence of fine particles. The specimen made only of coarse particles was then subjected to the same cyclic loading phase experienced by the eroded specimens. Figure 5 shows the build-up of EPWP at the end of the cyclic loading phase against the intergranular void ratio of each sample. 

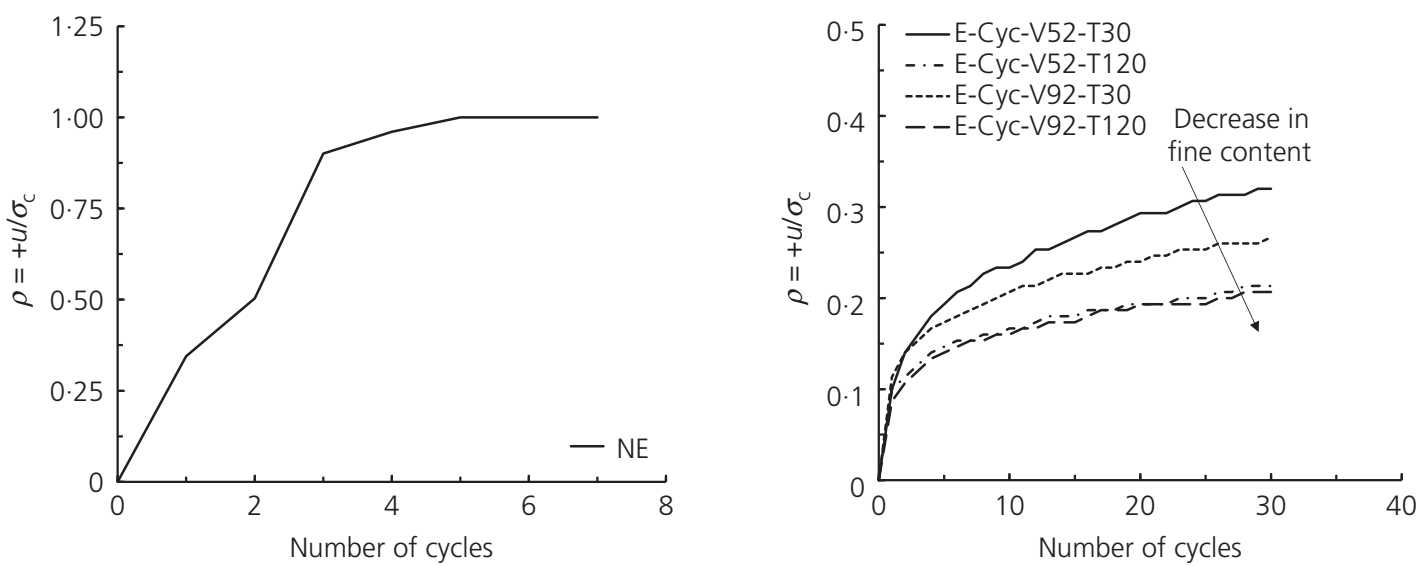

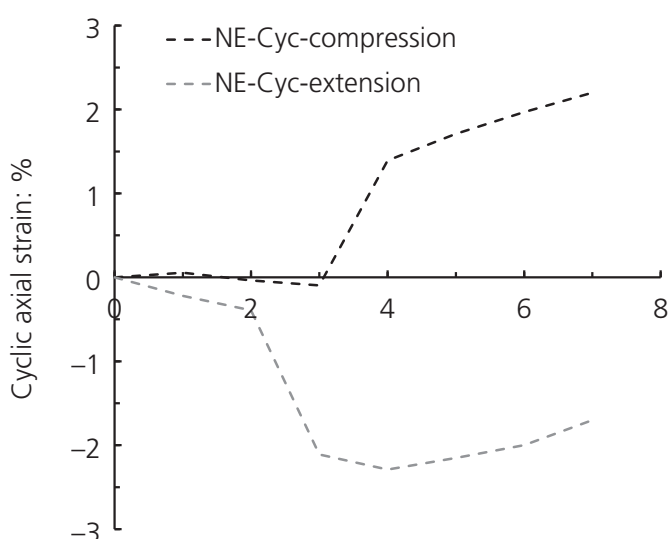

(a)

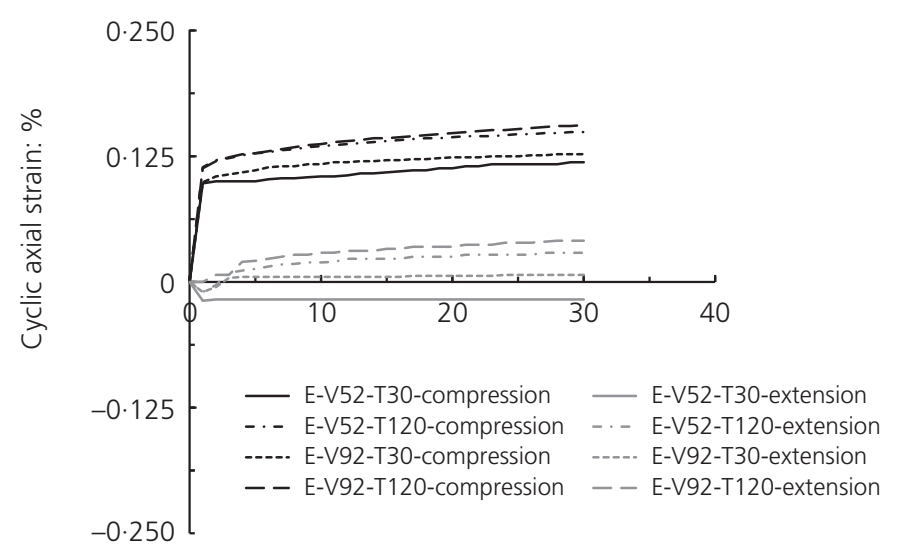

(b)

Fig. 2. Maximum induced excess pore pressure and axial strains during each cycle of loading: (a) non-eroded specimens and (b) eroded specimens
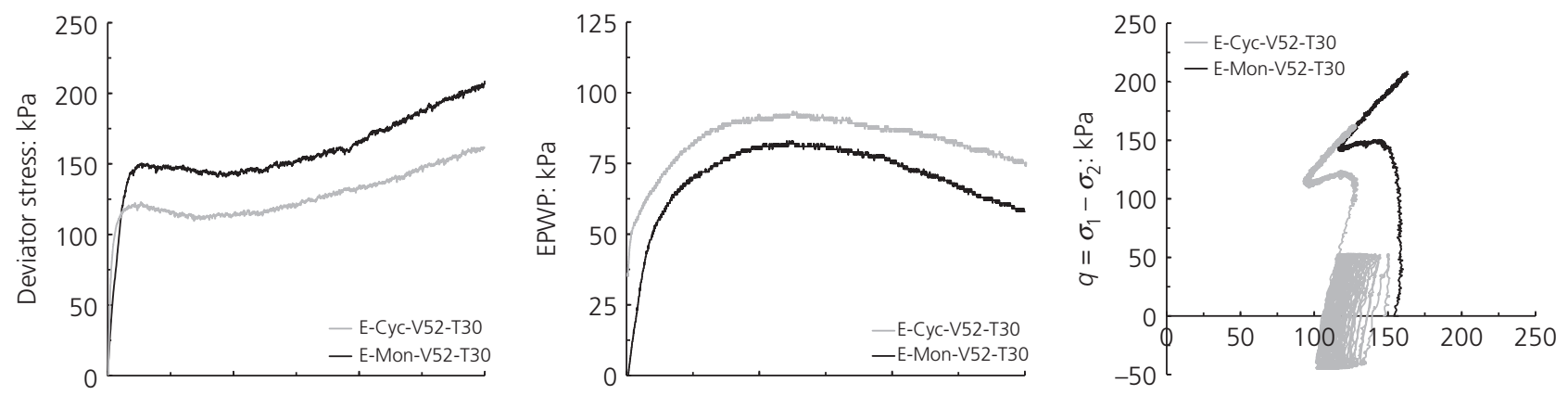

(a)
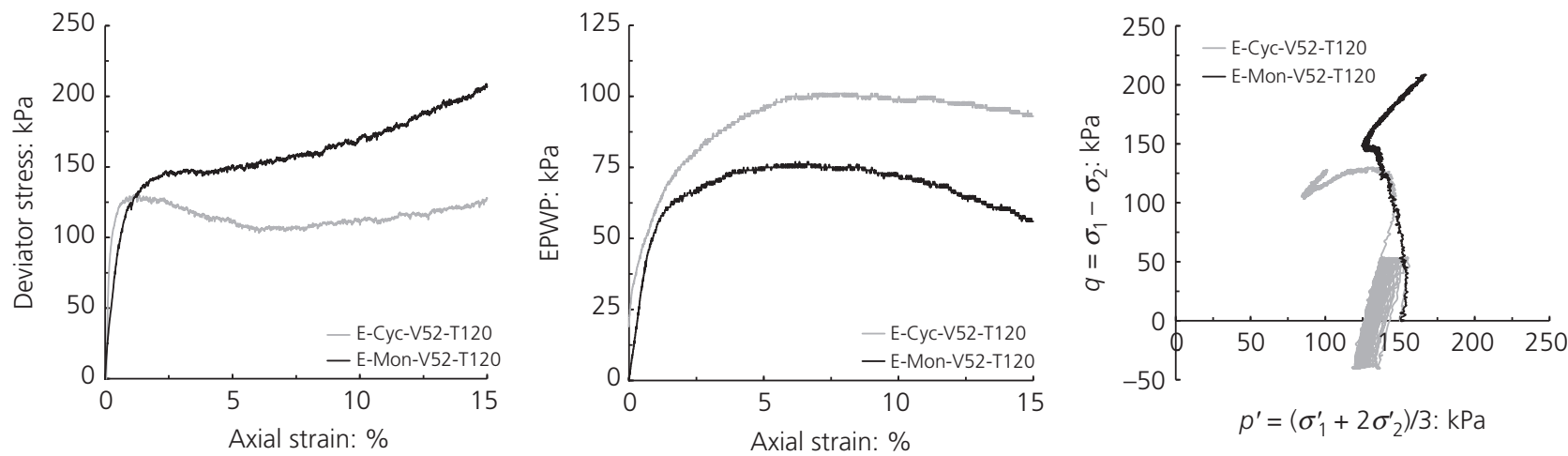

(b)

Fig. 3. Stress-strain relationship, induced EPWP and the stress path of eroded specimens, pre- and post-cyclic loading: (a) E-V52-T30 and (b) E-V52-T120 

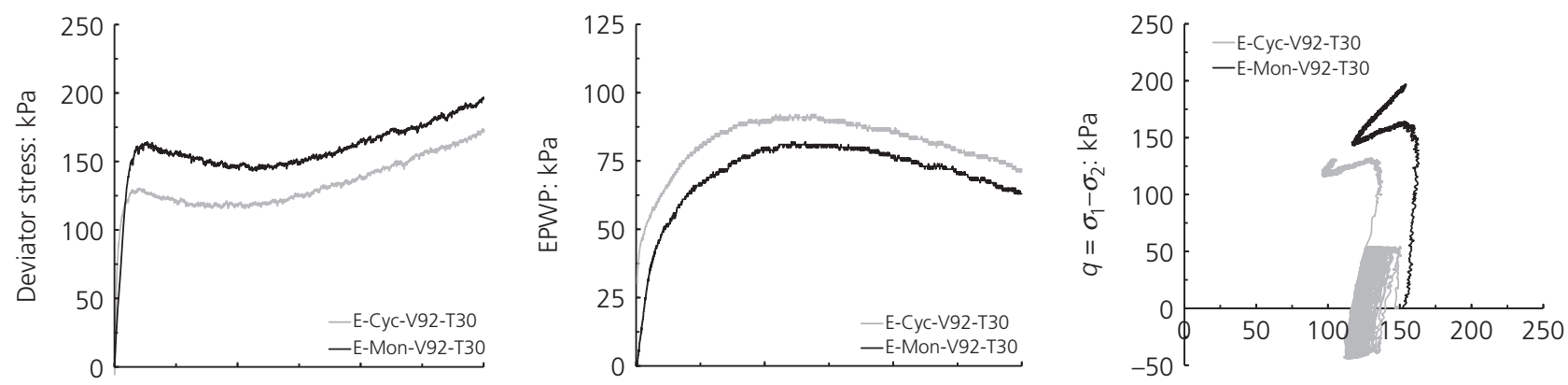

(a)
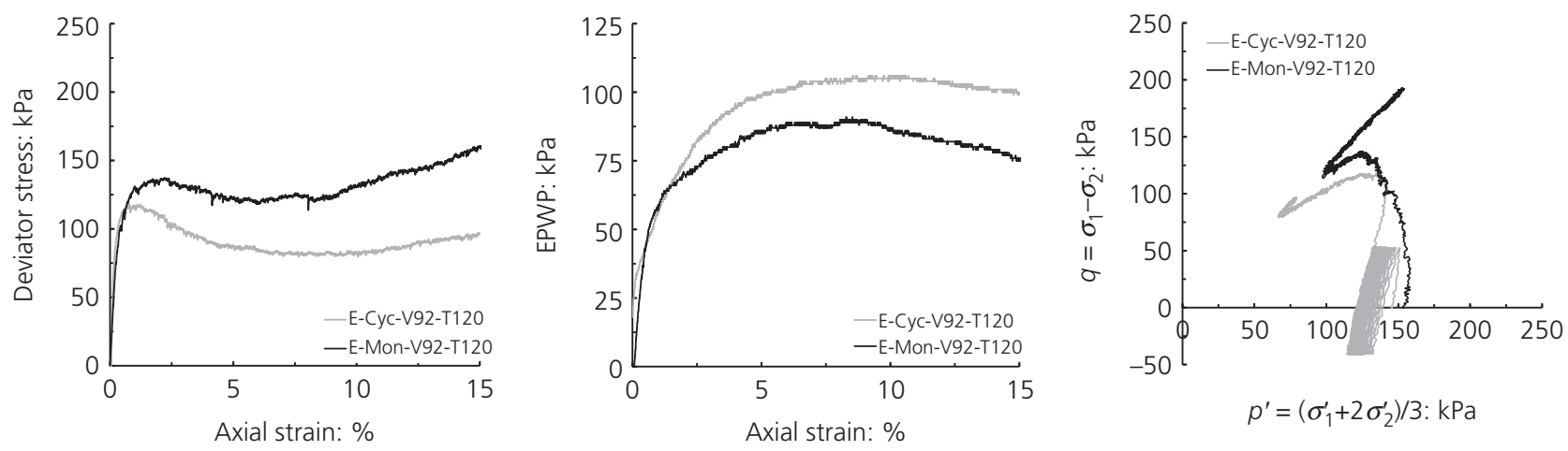

(b)

Fig. 4. Stress-strain relationship, induced EPWP and the stress path of eroded specimens, pre- and post-cyclic loading: (a) E-V92-T30 and (b) E-V92-T120

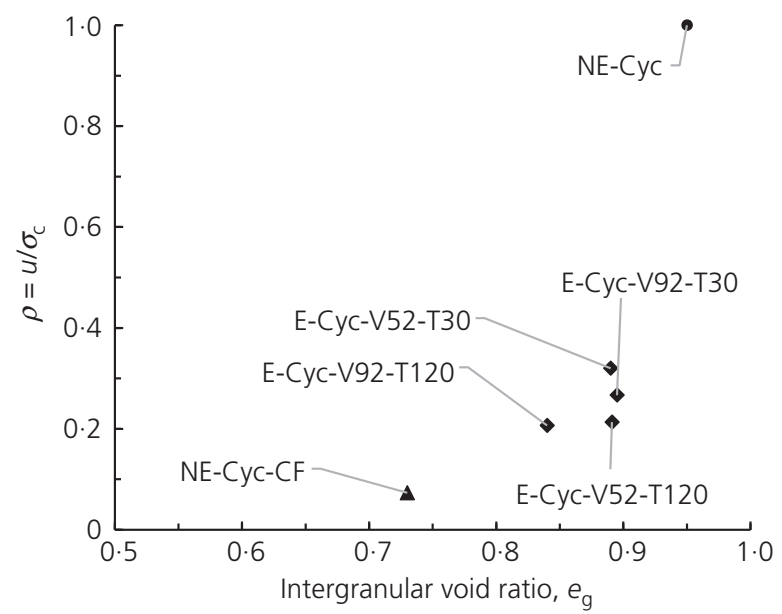

Fig. 5. Impact of intergranular void ratio on the development of excess pore-water pressure during cyclic loading

Interestingly, the eroded specimens tended to behave similarly to the soil specimen with no initial fine content (NE-Cyc-CF) during cyclic loading. Even the E-CycV52-T30 specimen with 20\% final fine content (5\% lower than initial) under cyclic loading shows a behaviour similar to that of the specimen with no fine content (NE-Cyc-CF). For this specimen, seepage flow only washed out $5 \%$ of the fine particles, but the consequent drop in induced EPWP was significant. Figure 5 indicates that considering only the residual fine content or the global void ratio to explain the cyclic behaviour of the eroded specimens is not accurate and it is the intergranular void ratio which controls the potential of liquefaction. This is supported by the observation that eroded specimens with higher global void ratios and lower intergranular void ratios were more cyclic-resistant than non-eroded specimens with much lower global void ratios and higher intergranular void ratios. Interestingly, this is in good agreement with the findings presented by Belkhatir et al. (2010) that the liquefaction resistance increases with a decrease in the intergranular void ratio. By an increase in the fine content, the fine particles start to fill more voids within the host sand matrix, and therefore, the contact between the sand particles decreases and thus the intergranular void ratio increases. Intergranular void ratio decreases during suffusion by two means. Erosion of fine particles not only lets the coarse particles come into better contact, but it also removes the secondary support of force chains made by coarse particles and causes local soil structure collapses which eventually decrease the available voids between particles. The result of this research is also in agreement with the findings of Lade \& Yamamuro (1997), Zlatovic \& Ishihara (1995), Thevanayagam et al. (1997), Amini \& Qi (2000) and Naeini \& Baziar (2004), confirming that, in contrast to the global void ratio, it is the intergranular void ratio that determines the behaviour of silty sands during cyclic loading. However, more tests on eroded specimens with different soil gradations and fine contents need to be performed to further validate this finding.

The post-cyclic behaviour of specimen E-Cyc-V92-T120, the specimen with the lowest fine content and intergranular void ratio and the highest global void ratio $\left(\mathrm{FC}_{\mathrm{i}}=25\right.$, $\mathrm{FC}_{\mathrm{f}}=10 \cdot 1 \%$ ), was compared directly with that of specimen NE-Cyc-CF $\left(\mathrm{FC}_{\mathrm{i}}=\mathrm{FC}_{\mathrm{f}}=0 \%\right)($ Figs 6 and 7). The global void ratio was 0.65 for the specimen E-V92-T120 after erosion and 0.73 for the specimen NE-Cyc-CF after consolidation. Apart from both specimens displaying nonliquefiable behaviour, they showed very different post-cyclic undrained behaviour patterns. A strain-hardening behaviour (dilation) with significant undrained shear strength was observed for the specimen NE-Cyc-CF while a 


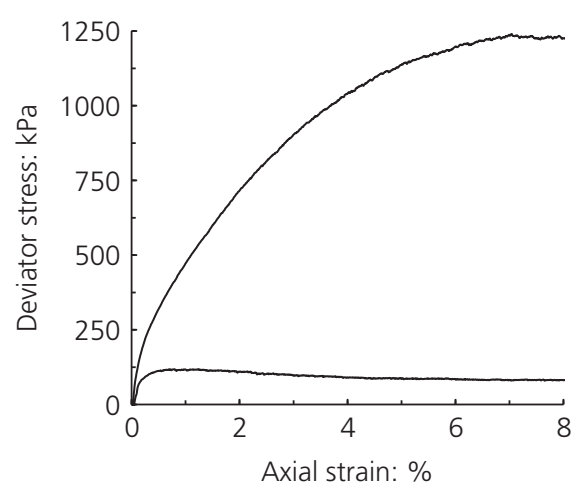

(a)

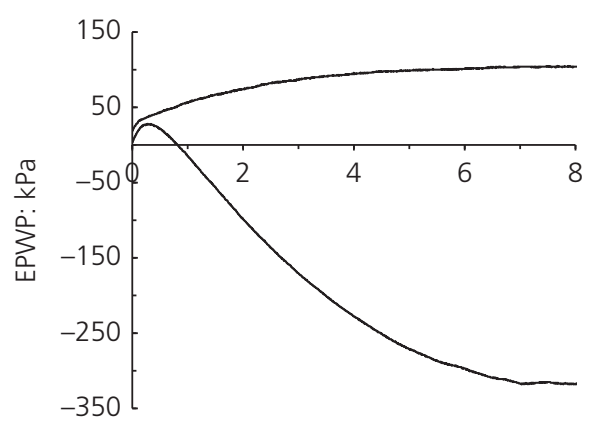

Axial strain: \%

(b)

Fig. 6. Post-cyclic monotonic shearing of NE-Cyc-CF and E-Cyc-V92-T120: (a) stress-strain relationship and (b) induced EPWP

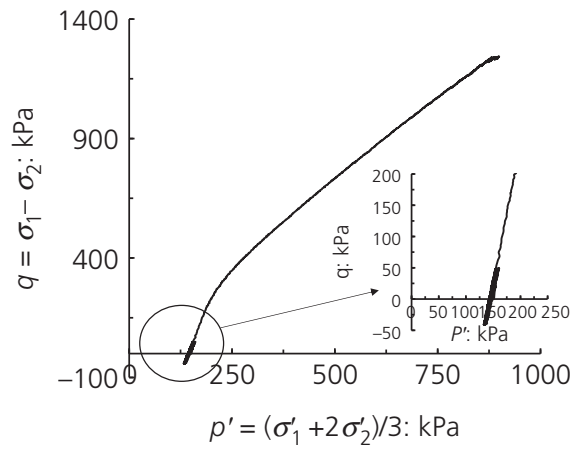

(a)

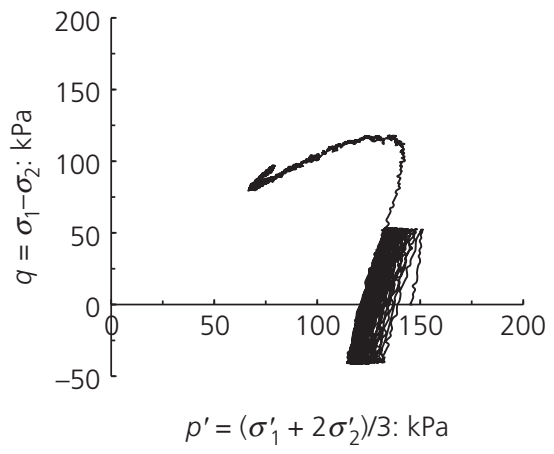

(b)

Fig. 7. Cyclic and post-cyclic stress path: (a) Cyc-CF and (b) E-Cyc-V92-T120

strain-softening behaviour (contraction) with limited flow deformation was dominant for the specimen E-Cyc-V92T120. This indicates that the presence of even a small amount of fine particles changed the soil-shearing response considerably. Particle-shape analysis was carried out and it was found that the angularity of the coarse particles between 1.7 and $2.36 \mathrm{~mm}$ in diameter was much higher than for the other particles (Mehdizadeh et al., 2017b). It is evident that in the specimen NE-Cyc-CF with higher particle angularity and much lower intergranular void ratio, a better interlock between coarse particles was formed, which led to a higher shear strength and dilative behaviour. Moreover, the lubricating effect of fine particles has been reported previously by Thevanayagam \& Mohan (2000), Thevanayagam (2007) and Ke \& Takahashi (2015). The concentration of more rounded fine particles between coarse particles in the specimen E-Cyc-V92-T120 reduced the coarse particle interlocking and increased the slip-down movement of particles and postponed the dilation tendency.

\section{CONCLUSION}

The influence of suffusion on the cyclic and post-cyclic behaviour of a gap-graded cohesionless soil was investigated using a combined triaxial-erosion system. It was found that the eroded specimens were cyclic-resistant regardless of the percentage of eroded particles. Moreover, the non-eroded specimens were quickly liquefied after only five cycles of loading (at $60 \%$ relative density and subjected to $150 \mathrm{kPa}$ of consolidation pressure). The lower potential of liquefaction for the eroded specimens was found to be due to a decrease in the intergranular void ratio after the erosion of fine particles. Although the erosion of fine particles caused an increase in the global void ratio, it did increase the contact between coarse particles due to particle rearrangement. This change in soil structure naturally improved the soil resistance against liquefaction. Moreover, the eroded samples when subjected to cyclic loading showed a softer behaviour in comparison with the eroded specimens not subjected to cyclic loading. This was due to the build-up of excess pore pressure in the range of $20-30 \%$ of the consolidation pressure during cyclic loading.

\section{REFERENCES}

Amini, F. \& Qi, G. Z. (2000). Liquefaction testing of stratified silty sands. J. Geotech. Geoenviron. Engng 126, No. 3, 208-217.

Andrianopoulos, K., Bouckovalas, G. \& Papadimitriou, A. (2001). A critical state evaluation of fines effect on liquefaction potential. Proc. 4th int. conf. on recent advances in geotechnical earthquake engineering and soil dynamics and Symposium in Honor of Professor W.D. Liam Finn, San Diego, California, Paper 4.06.

Belkhatir, M., Arab, A., Della, N., Missoum, H. \& Schanz, T. (2010). Influence of inter-granular void ratio on monotonic and cyclic undrained shear response of sandy soils. Comp. Rendus Méc. 338, No. 5, 290-303.

Chameau, J. L. \& Sutterer, K. (1994). Influence of fines in liquefaction potential and steady state considerations. Proc. 13th int. conf. of soil mechanics and foundation engineering, New Delhi, India, 5, pp. 183-184. Rotterdam, The Netherlands: Balkema.

Chang, N. Y. (1990). Influence of fines content and plasticity on earthquake-induced soil liquefaction, contract report, MS Cont. DACW3988-C-0078. Vicksburg, MS, USA: US Army Waterways Experiment Station.

Chu, J. \& Leong, W. K. (2002). Effect of fines on instability behaviour of loose sand. Géotechnique 52, No. 10, 751-755. 
Evans, M. D. \& Zhou, S. (1995). Liquefaction behaviour of sand-gravel composites. J. Geotech. Engng 121, No. 3, 287-298.

Finn, L. W. D., Ledbetter, R. H. \& Guoxi, W. U. (1994). Liquefaction in silty soils: design and analysis. Geotech. Spec. Publ. ASCE 44, 51-76.

Frost, J. D. \& Park, J. Y. (2003). A critical assessment of the moist tamping technique. Geotech. Test. J. 26, No. 1, $57-70$.

Georgiannou, V. N., Hight, D. W. \& Burland, J. B. (1990). The undrained behaviour of clayey sands in triaxial compression and extension. Géotechnique 40, No. 3, 431-449.

Georgiannou, V. N., Hight, D. W. \& Burland, J. B. (1991a). Undrained behaviour of natural and model clayey sands. Soils Found. 31, No. 3, 17-29.

Georgiannou, V. N., Hight, D. W. \& Burland, J. B. (1991b) Behaviour of clayey sands under undrained cyclic triaxial loading. Géotechnique 41, No. 3, 383-393.

Jiang, M. J., Konrad, J. M. \& Leroueil, S. (2003). An efficient technique for generating homogeneous specimens for DEM studies. Comput. Geotech. 30, No. 7, 579-597.

Ke, L. \& Takahashi, A. (2014). Triaxial erosion test for evaluation of mechanical consequences of internal erosion. Geotech. Test. J. 37, No. 2, 1-18.

Ke, L. \& Takahashi, A. (2015). Drained monotonic responses of suffusional cohesionless soils. J. Geotech. Geoenviron. Engng 148, No. 8, 04015033.

Kenney, T. C. \& Lau, D. (1986). Internal stability of granular filters: reply. Can. Geotech. J. 23, No. 4, 420-423.

Kezdi, A. (1969). Increase of protective capacity of flood control dikes, Report 1. Budapest, Hungary: Department of Geotechnique, Technical University.

Koester, J. P. (1994). The influence of fines type and content on cyclic strength. Geotech. Spec. Publ. ASCE 44: 17-32.

Kuerbis, R., Negussey, D. \& Vaid, Y. P. (1988). Effect of gradation and fines content on the undrained response of sand. In Hydraulic fill structures (eds D. J. A. Van Zyl and S. G. Vick), Geotechnical Special Publication no. 21, pp. 330-345. New York, NY, USA: ASCE.

Ladd, R. S. (1978). Preparing test specimens using undercompaction. Geotech. Test. J. 1, No. 1, 16-23.

Lade, P. V. \& Yamamuro, J. A. (1997). Effects of nonplastic fines on static liquefaction of sands. Can. Geotech. J. 34, No. 6, 918-928.

Mehdizadeh, A. (2018). Multi scale investigation of post-erosion mechanical behaviour of granular material. $\mathrm{PhD}$ thesis, Swinburne University of Technology, Melbourne, Australia

Mehdizadeh, A. \& Disfani, M. M. (2018). Micro scale study of internal erosion using 3D X-ray tomography. Proceedings of the 9 th international conference on scour and erosion, Taipei, Taiwan, pp. 19-26.
Mehdizadeh, A., Disfani, M. M., Evans, R. P., Arulrajah, A. \& Ong, D. E. L. (2015). Discussion of 'Development of an internal camera-based volume determination system for triaxial testing' by S. E. Salazar, A. Barnes, and R. A. Coffman. Geotech. Test. J. 38, No. 1, 165-168.

Mehdizadeh, A., Disfani, M. M., Evans, R. P., Arulrajah, A. \& Ong, D. E. L. (2017a). Mechanical consequences of suffusion on undrained behaviour of a gap-graded cohesionless soil - ann experimental approach. Geotech. Test. J. 40, No. 6, 20160145, https://doi.org/10.1520/GTJ20160145.

Mehdizadeh, A., Disfani, M. M., Evans, R. P. \& Arulrajah, A. (2017b). Progressive internal erosion in a gap-graded internally unstable soil-mechanical and geometrical effects. Int. $J$. Geomech. 18, No. 3, 04017160.

Mitchell, J. K. (1993). Fundamentals of soil behaviour. New York, USA: John Wiley \& Sons.

Moraci, N., Mandaglio, M. C. \& Ielo, D. (2014). Analysis of the internal stability of granular soils using different methods. Can. Geotech. J. 51, No. 9, 1063-1072.

Naeini, S. A. \& Baziar, M. H. (2004). Effect of fines content on steady-state strength of mixed and layered samples of a sand. J. Soil Dyn. Earthq. Engng 24, No. 3, 181-187.

Pitman, T. D., Robertson, P. K. \& Sego, D. C. (1994). Influence of fines on the collapse of loose sands. Can. Geotech. J. 31, No. 5, 728-739.

Thevanayagam, S. (1998). Effect of fines and confining stress on undrained shear strength of silty sands. J. Geotech. Geoenviron. Engng 124, No. 6, 479-491.

Thevanayagam, S. (2007). Intergrain contact density indices for granular mixes-I: framework. Earthq. Engng Engng Vibr. 6, No. 2, 123-134.

Thevanayagam, S. \& Mohan, S. (2000). Intergranular state variables and stress-strain behaviour of silty sands. Géotechnique 50, No. 1, 1-23.

Thevanayagam, S., Ravishankar, K. \& Mohan, S. (1997). Effects of fines on monotonic undrained shear strength of sandy soils. Geotech. Test. J. 20, No. 4, 394-406.

Vaid, Y. P. (1994). Liquefaction of silty soils. Ground failures under seismic conditions. Geotech. Spec. Publ. 44, 1-16.

Xenaki, V. C. \& Athanasopoulos, G. A. (2003). Liquefaction resistance of sand-silt mixtures: an experimental investigation of the effect of fines. J. Soil Dyn. Earthq. Engng 23, No. 3, 1-12.

Yang, S. L., Lacasse, S. \& Sandven, R. F. (2006). Determination of the transitional fines content of mixtures of sand and non-plastic fines. Geotech. Test. J. 29, No. 2, 102-107.

Zlatovic, S. \& Ishihara, K. (1995). On the influence of nonplastic fines on residual strength. In Proc. IS-TOKYO'95 1st int. conf. on earthquake geotechnical engineering, Tokyo, Japan (ed. K. Ishihara), vol. 1, pp. 239-244. Rotterdam, The Netherlands: Balkema. 